\title{
CONSTRUCTION OF DISASTER PREVENTION CAPABILITY EVALUATION FRAMEWORK OF URBAN PARK SYSTEM: METHODOLOGY AND ITS APPLICATION IN CHINA
}

\author{
Wenjun FEI ${ }^{1}$, Jiyang WU ${ }^{1}$, Ying $\mathrm{SHI}^{2}$, Qi $\mathrm{CHEN}^{3}$ \\ ${ }^{1}$ College of Landscape Architecture, Nanjing Forestry University, Nanjing, 210000, China \\ ${ }^{2}$ College of Horticulture, Jinling Institute of Technology, Nanjing 210000, China \\ ${ }^{3}$ Graduate School of Human-Environment Studies, Kyushu University, Fukuoka, 8190382, Japan
}

Received 11 February 2019; accepted 10 July 2019

\begin{abstract}
The construction of disaster prevention capability evaluation framework is the basic requirement of building a sustainable and harmonious society under the background of urban public security. This study had constructed a framework for disaster prevention capability assessment of urban park systems applicable to China through rigorous logical reasoning and careful selection of indicators. The framework contains 4 first-level indicators and 8 second-level indicators and 21 third-level indicators. Quantitative methods and calculating procedures for each indicator and dynamic weight were also given in this paper. Finally, in order to prove the practical value of the evaluation system designed in this study, five cities in China were selected for application. The results showed that the indicator system can not only accurately quantify the disaster prevention capability of the urban park system, but also discover the shortcomings in the process of urban park system construction, which has strong theoretical and practical value.
\end{abstract}

Keywords: urban park, disaster prevention capability, evaluation framework.

\section{Introduction}

China is a country with frequent natural and man-made disasters. The outbreak of disasters such as earthquakes, floods, fires, debris flows and so on will generate a large number of displacement and resettlement needs of the affected people (Liang, 2015). Therefore, the construction of disaster prevention and refuge sites is the basic requirement of building a sustainable and harmonious society under the background of urban public security (Ding et al., 2015).

Urban parks have the most perfect functions and facilities in the whole urban green space system (Rigolon, 2016). They have open spaces, convenient road traffic, natural green plant barriers and suitable water reserve system (Brink et al., 2016). They are important places for leisure and entertainment, and also one of the main types of urban emergency shelter (Haaland \& van den Bosch, 2015). Urban parks usually have the characteristics of wide distribution, rich types and high utilization rate of residents. As a green disaster prevention space, urban parks can meet the needs of urban residents in the whole process of temporary emergency evacuation, follow-up security transfer, medium and long-term shelter, and provide protection for disaster-avoiding population to receive rescue (Opitz, Berges, Piorr, \& Krikser, 2016). Urban parks are the core components of urban disaster prevention and risk avoidance green space system, and the disaster prevention and risk avoidance planning of urban parks is also the leader of all kinds of disaster prevention planning and construction (Wei, Huang, Li, \& Xie, 2016).

Therefore, based on the characteristics of urban historical disasters, the construction of urban disaster prevention space and the current situation of park green space system, it is imperative to construct a reasonable and efficient urban disaster prevention and avoidance park green space system from the urban level. Its primary task is to construct a disaster prevention capability evaluation framework of urban park system, quantitatively analyze the disaster prevention ability of urban park green space system, and accurately find the shortcomings of urban park green space system construction (Haaland \& van den Bosch, 2015).

*Corresponding author. E-mail: sying1213@outlook.com 


\section{Related work}

Researchers have long been aware of the relationship between urban park construction and urban disaster prevention, and scholars all over the world have carried out research on it (Zhang, Li, \& Wang, 2015). As early as the early and mid-17th century in Europe, some scholars put forward the theory of disaster prevention planning, that is, to arrange strip parks and greenbelts on both sides of straight and wide urban avenues to form a fire-proof green belt, and to plan the evacuation and evacuation of people from disasters connected with super-large squares (Güzey, 2016). Later, this theory was applied to the urban planning of Catania, Italy, and Lisbon, Portugal. It was regarded as the embryonic form of urban disaster prevention green space system (La Rosa, Privitera, Barbarossa, \& La Greca, 2017). In the late 19th century, Chicago was damaged by fire. American scholars began to realize the important contribution of urban parks to urban disaster prevention (Smith, 2007). They use parks and greenways to divide urban areas with high building density, and use open space layout to prevent fire spread and improve the city's ability to resist natural disasters (Elliott, Walters, \& Wright, 2016). The research results of American scholars have become the pioneers of disaster prevention green space system planning. After "9.11", the United States began to plan disaster-proof communities, combining community parks with disaster refuge functions (Robles, Tello, Zúñiga-Prieto, \& Solano-Quinde, 2018). In addition, the United States had also strictly regulated the implementation process of disaster prevention and hedging, and urged the implementation of pre-disaster, disaster avoidance and recovery measures as soon as possible, which had also promoted the global upsurge of research on modern disaster prevention and hedging green space (Ortolano, 2017).

Chinese green space researchers have been devoting themselves to the study of the layout and structure of green space in China for a long time, and their research results have also been widely used in the construction of urban recreational green space system (Kibert, 2016). In 2017, China announced a new classification standard of green space, which also indicates that Chinese academia is about to usher in a new upsurge of green space system research. Under this opportunity, Chinese scholars should start to study the construction of urban disaster prevention green space system (Somma et al., 2016). As mentioned above, urban parks are urban green spaces that can really play a role in the event of disasters (Thierfelder \& Kabisch, 2016). Therefore, the urban disaster prevention green space system is actually the transformation of the urban park system when disaster occurs. If we want to achieve the goal of building China's disaster prevention green space system, we first need to evaluate the disaster prevention and risk avoidance ability of China's urban parks, and find that the existing urban park system may have shortcomings in the face of disasters. We can improve the existing disaster prevention green space system by filling these shortcomings (Li, Sutton, Anderson, \& Nouri, 2017).
Based on this, this study will introduce a set of theoretical methods to evaluate the disaster prevention capability of urban park system from the urban level (Xiao, Li, $\&$ Webster, 2016). Firstly, we will introduce the construction process of the evaluation index system for the disaster prevention capability of urban park system proposed. Then we will elaborate how to use this index system to quantitatively analyze the disaster prevention capability of urban park system (Fan, Xu, Yue, \& Chen, 2017). Finally, we will explain how to find the shortcomings of the urban park system and put forward the corresponding optimization strategies based on the quantitative analysis results. It is believed that with the deepening of future research, the goal of building China's disaster prevention green space system will eventually be achieved.

\section{Construction of disaster prevention capability evaluation framework of urban park system}

Whether the urban park system is complete and continuous determines whether the urban disaster prevention and relief work can proceed smoothly. In the city, the park green space with various functions and complete facilities cooperates with each other in the urban spatial layout and function orientation, forming the urban park green space system. This system not only has the usual functions of ecology, landscape, recreation, culture and education, but also has the function of reducing the spread of secondary disasters, realizing the interactive disaster-time functions of rescue evacuation and disaster-avoidance resources sharing. It is an important green disaster prevention space in cities. The dynamic mechanism of urban disaster prevention and avoidance is formed by the cooperation between it and other disaster prevention spaces.

\subsection{Establishment of evaluation index system framework}

So if we need to build a comprehensive and accurate evaluation system to measure the disaster prevention capability of the urban park system, what aspects should we consider? This research has launched the following thinking (Figure 1).

After reviewing the relevant literature (Somma et al., 2016; Li, Fan, \& Shen, 2018), we conclude that the evaluation index system of disaster prevention ability of urban park system should be able to depict the efficiency of its disaster prevention function in the three periods of predisaster prevention, evacuation during disasters and reconstruction after disasters. At the same time, the relationship between urban park and urban residents should be taken into account.

Firstly, in the pre-disaster prevention stage, the study on the suitability of the park green space system for disaster prevention and risk avoidance should be based on a full understanding of the urban site conditions. By accurately analyzing the historical disaster situation of cities (i.e. the type, intensity and frequency of the disaster 


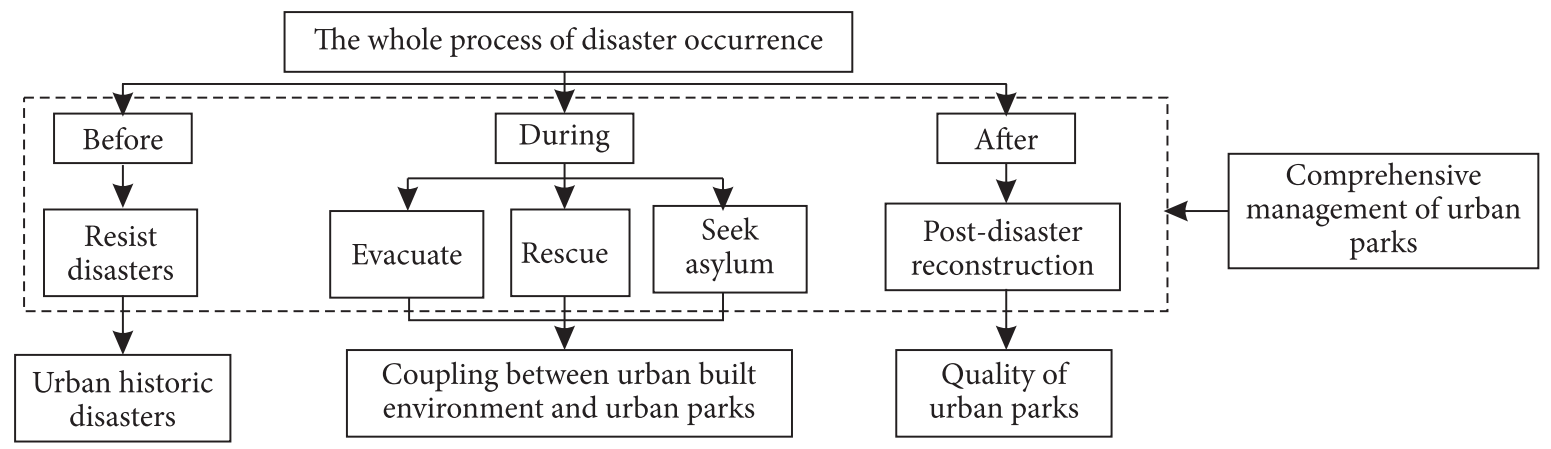

Figure 1 . The framework of index system

in history), we can judge whether the urban park green space system can meet the functional needs of the city in response to various disasters.

Secondly, as a complex giant system, cities depend on and influence each other, especially in case of disasters. Therefore, in the process of refuge, evacuation and rescue, the urban park system should be placed in the urban comprehensive disaster prevention system, and the evaluation of its disaster prevention and risk avoidance ability should be combined with its coordinate degree of other types of urban land, urban disaster prevention space and public infrastructure.

In addition, in the process of refuge and resettlement, the quality of urban parks is the key factor to judge the ability of disaster prevention and avoidance. The quality of the park, such as its area, structure and function layout, is very important to the extent to which the city park can undertake the function of refuge in the event of disaster. Only the urban park system composed of a large number of high-quality parks can meet the needs of people for shelter and post-disaster resettlement.

Finally, the urban park system needs an efficient disaster mitigation and transformation mechanism at all stages before and after the disaster. We also need to consider the comprehensive management measures and laws and regulations that support the smooth transformation of its peacetime functions and disaster functions, which are also an important part of the evaluation index system.

Based on the four key issues mentioned above, we put forward an evaluation index system consisting of four first-level indicators, eight second-level indicators and 21 third-level indicators (Table 1).

\subsection{Determining the weight of evaluation index}

After the construction of the suitability evaluation index system, the weight of each index should be determined according to the importance of each index. According to the different sources of raw data when calculating the weights, the methods of determining the weights of evaluation indexes can be divided into three categories: subjective weighting method, objective weighting method and combination weighting method. The mathematical theory of combination weighting method is relatively perfect, but its complexity is high and its applicability is relatively
Table 1. Evaluation system for disaster prevention and avoidance suitability of urban park greenspace

\begin{tabular}{|c|c|c|}
\hline $\begin{array}{c}\text { First Level } \\
\mathrm{A}\end{array}$ & Second Level B & Third Level C \\
\hline \multirow{6}{*}{$\begin{array}{l}\text { Quality } \\
\text { of Urban } \\
\text { Parks } A 1\end{array}$} & \multirow{2}{*}{$\begin{array}{l}\text { Total amount of } \\
\text { urban parks } B 1\end{array}$} & Sum of effective service area $C 1$ \\
\hline & & $\begin{array}{l}\text { Total Number of Effective Parks } \\
\text { and Greenbelts } C 2\end{array}$ \\
\hline & \multirow{4}{*}{$\begin{array}{l}\text { Rationality of } \\
\text { the layout and } \\
\text { structure of } \\
\text { urban park } B 2\end{array}$} & Diversity of Urban Parks C3 \\
\hline & & Uniformity of Urban Parks $C 4$ \\
\hline & & Connectivity of Urban Parks C5 \\
\hline & & $\begin{array}{l}\text { Conglomeration Degree of } \\
\text { Urban Parks C6 }\end{array}$ \\
\hline \multirow{5}{*}{$\begin{array}{l}\text { Coupling } \\
\text { between } \\
\text { Urban } \\
\text { Built } \\
\text { Environ- } \\
\text { ment and } \\
\text { Urban } \\
\text { Parks A2 }\end{array}$} & \multirow{3}{*}{$\begin{array}{l}\text { Connectivity } \\
\text { between } \\
\text { urban built } \\
\text { environment } \\
\text { elements and } \\
\text { urban parks B3 }\end{array}$} & $\begin{array}{l}\text { Matching Degree with Urban } \\
\text { Traffic Network C7 }\end{array}$ \\
\hline & & $\begin{array}{l}\text { Connectivity with urban } \\
\text { disaster relief facilities } C 8\end{array}$ \\
\hline & & $\begin{array}{l}\text { Connectivity with other urban } \\
\text { disaster prevention spaces } C 9\end{array}$ \\
\hline & \multirow{2}{*}{$\begin{array}{l}\text { The Matching } \\
\text { Degree between } \\
\text { Urban Built } \\
\text { Environment } \\
\text { Elements and } \\
\text { the Number of } \\
\text { Urban Parks } B 4\end{array}$} & $\begin{array}{l}\text { Quantitative Matching Degree } \\
\text { with Urban Population Density } \\
\text { C10 }\end{array}$ \\
\hline & & $\begin{array}{l}\text { Matching Degree with } \\
\text { the Quantity of Urban } \\
\text { Infrastructure } C 11\end{array}$ \\
\hline \multirow{5}{*}{$\begin{array}{l}\text { Urban } \\
\text { Historic } \\
\text { Disasters } \\
\text { A3 }\end{array}$} & \multirow{3}{*}{$\begin{array}{l}\text { Disaster } \\
\text { occurrence B5 }\end{array}$} & Disaster Intensity Index C12 \\
\hline & & Disaster Frequency Index C13 \\
\hline & & $\begin{array}{l}\begin{array}{l}\text { Previous abnormal } \\
\text { environmental events } C 14\end{array} \\
\end{array}$ \\
\hline & \multirow{2}{*}{$\begin{array}{l}\text { Disaster } \\
\text { severity } B 6\end{array}$} & $\begin{array}{l}\text { Economic losses caused by } \\
\text { previous disasters } C 15\end{array}$ \\
\hline & & $\begin{array}{l}\text { Casualties caused by previous } \\
\text { disasters } C 16\end{array}$ \\
\hline \multirow{5}{*}{$\begin{array}{l}\text { Compre- } \\
\text { hensive } \\
\text { Mana- } \\
\text { gement } \\
\text { of Urban } \\
\text { Parks A4 }\end{array}$} & \multirow{3}{*}{$\begin{array}{l}\text { The } \\
\text { Completeness } \\
\text { of Relevant } \\
\text { Laws and } \\
\text { Regulations } B 7\end{array}$} & $\begin{array}{l}\text { Planning Completeness of } \\
\text { Green Space System C17 }\end{array}$ \\
\hline & & $\begin{array}{l}\text { Completeness of Urban Disaster } \\
\text { Prevention Planning C18 }\end{array}$ \\
\hline & & $\begin{array}{l}\text { Completeness of other relevant } \\
\text { design guidelines C19 }\end{array}$ \\
\hline & \multirow{2}{*}{$\begin{array}{l}\text { Urban Disaster } \\
\text { Prevention } \\
\text { Mechanism B8 }\end{array}$} & $\begin{array}{l}\text { Unified command capability } \\
\text { C20 }\end{array}$ \\
\hline & & $\begin{array}{l}\text { Synergistic linkage mechanism } \\
\text { C21 }\end{array}$ \\
\hline
\end{tabular}


weak. Therefore, we will analyze the advantages and disadvantages of subjective and objective weight determination methods and find the most suitable ones for this study.

\subsubsection{Selection of weights determination methods}

Subjective weighting method is a way to determine the weight according to the degree of decision makers' subjective attention, which mainly includes expert investigation method, analytic hierarchy process, fuzzy analysis method and so on. This method can combine expert experience with practical problems. At present, it is commonly used in landscape evaluation, safety evaluation, function evaluation, disaster prevention and avoidance park planning and research. However, it is vulnerable to the limitations of decision makers themselves, and has a strong subjective arbitrariness.

The objective weighting method is based on the actual data in decision-making to determine the weight, mainly including the entropy method, principal component analysis method and so on. This method has strong objectivity and is commonly used in multi-objective attribute assessment, resource and environment carrying capacity assessment and urbanization development assessment. However, it cannot reflect the importance of decision-makers to different elements, and the weight may be inconsistent with the actual situation.

The experience of relevant research and practice tells us that the combination of subjective and objective weight determination methods can improve the accuracy of calculation results.

\subsubsection{Comprehensive weight determination methods}

In the subjective weighting method, the expert investigation method is more comprehensive, reliable and simple than other methods. Analytic hierarchy process (AHP) can hierarchize complex problems and quantify qualitative problems, which makes the analytical method clear and systematic (Hoang \& Fenner, 2016). In the objective weighting method, the calculation process of the entropy method and the principal component analysis method is

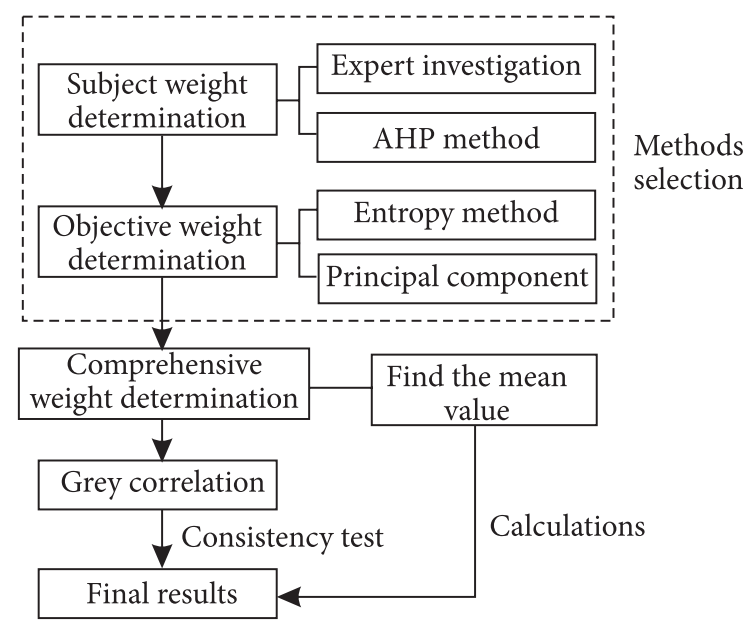

Figure 2. How to determine the weights relatively simple and operable, and the principal component analysis method can determine the correlation between the indicators.

Therefore, this study chooses the above four methods to determine the weights of factors, which can make up for the shortcomings of a single way of empowerment, and thus improve the scientific evaluation results. The specific process is as follows (Figure 2).

\subsection{Quantification of indicators at all levels in the evaluation index system}

In the previous chapter, after rigorous logical reasoning, this study formally launched the evaluation index of suitability for disaster prevention and avoidance of urban parks in China. However, there are still a lot of abstract and quantitative indicators in the index system (especially the third-level indicators). How to convert these abstract indicators into precise numbers scientifically and accurately determines the scientificity of the index system to a great extent. Therefore, in this section, we will introduce in detail how to quantify the indicators of each level, how to use weight determination algorithm to integrate the quantitative results of indicators into accurate values that can reflect the disaster prevention ability of urban parks.

\subsubsection{Data collection and processing}

The first step in the process of quantifying evaluation indicators is to collect relevant data. The data needed in the process of using the quantitative index system designed in this study include:

Table 2. Data and sources

\begin{tabular}{|l|l|}
\hline \multicolumn{1}{|c|}{ Name } & \multicolumn{1}{c|}{ Source } \\
\hline Disaster intensity & China Urban Statistics Yearbook \\
\hline Number of disasters & China Urban Statistics Yearbook \\
\hline $\begin{array}{l}\text { Number of Abnormal } \\
\text { Environmental Events }\end{array}$ & China Urban Statistics Yearbook \\
\hline $\begin{array}{l}\text { Economic losses caused by } \\
\text { disasters }\end{array}$ & China Urban Statistics Yearbook \\
\hline $\begin{array}{l}\text { Casualties caused by } \\
\text { disasters }\end{array}$ & China Urban Statistics Yearbook \\
\hline Number of urban parks & $\begin{array}{l}\text { Remote Sensing images, Field } \\
\text { survey }\end{array}$ \\
\hline Location of urban parks & $\begin{array}{l}\text { Remote Sensing images, Field } \\
\text { survey }\end{array}$ \\
\hline Area of urban parks & Remote Sensing images \\
\hline $\begin{array}{l}\text { Vector Data of Urban } \\
\text { Traffic Network }\end{array}$ & OpenStreetMap \\
\hline $\begin{array}{l}\text { Vector Data of Urban } \\
\text { Disaster Relief Facilities }\end{array}$ & OpenStreetMap \\
\hline $\begin{array}{l}\text { Other Urban Disaster Pre- } \\
\text { vention Spatial Vector Data }\end{array}$ & OpenStreetMap \\
\hline Urban Population Density & City Population \\
\hline $\begin{array}{l}\text { Vector Data of Urban } \\
\text { infrastructure }\end{array}$ & OpenStreetMap \\
\hline Type of urban parks & Field survey \\
\hline $\begin{array}{l}\text { Relevant Planning, Laws } \\
\text { and Regulations Documents }\end{array}$ & $\begin{array}{l}\text { China Civil Administration } \\
\text { Department }\end{array}$ \\
\hline
\end{tabular}


In Table 2, We have listed the names and sources of all the raw data needed in this study. Next, we will give a detailed description of the data presented in the table above. Data that need further elaboration include the source, accuracy and use of remote sensing maps, the use of OSM platforms and the use of data from the City Population website.

\section{(1) Remote sensing}

All the images used in this study are from Landsat 8 satellite. There are 11 bands in the satellite image, the spatial resolution of band $1-7,9-11$ is 30 meters, and band 8 is 15 meters resolution panchromatic band (this study mainly uses 3, 4, 5 bands to study green spaces).

In the process of processing remote sensing images, high-quality remote sensing images are first obtained from geospatial data clouds and China Resources Satellite Center. After obtaining the high-resolution image of the park green space, all the green areas in the study area were initially extracted using the supervised classification tool in the ENVI remote sensing image processing platform. Finally, combined with on-site investigation, reviewing the map, manually classifying the extracted park green space. The addition of remote sensing technology can help us quickly obtain important information such as the location and area of each urban park green space, greatly reducing the complexity of data processing.

\section{(2) OpenStreetMap}

OpenStreetMap (OSM) is a collaborative project to create a free editable map of the world. Rather than the map itself, the data generated by the project is considered its primary output. The creation and growth of OSM has been motivated by restrictions on use or availability of map information across much of the world, and the advent of inexpensive portable satellite navigation devices. OSM is considered a prominent example of volunteered geographic information.

\section{(2) City Population}

City Population website (https://www.citypopulation.de/) is a website specializing in collecting census data from countries and regions around the world. This site usually visualizes these demographic data in the form of graphs and tables. Within China, it can provide data on the total population of each street in each prefecture-level city, updated between 2011 .

\subsubsection{Quantification of evaluation indicators}

In this section, we will introduce how to use the data collected earlier, and how to convert these data into the specific values of each indicator.

\section{(1) Total amount of urban parks}

The total amount of urban park includes the sum of effective service area and the total number of effective urban park. The calculation of each index is based on remote sensing images, and the statistics are carried out in combination with urban planning texts and field research.
Remote sensing image data and field survey data are needed to calculate the sum of effective service areas. Firstly, the vector data of urban parks are extracted by combining ENVI and visual interpretation, and the total area of parks within the built-up area of the city is calculated. Then, based on the field investigation, highrise buildings around the urban park, buildings with low seismic grade, chemical plants, nuclear power plants and other artificial secondary disaster sources are marked on the vector map, and the radiation range of these secondary disaster sources is plotted by using the buffer analysis function of ArcGIS software. Finally, the cutting operation function is used in ArcGIS software to subtract the radiation area of these disaster sources from the total area of the park, and the sum of the effective service areas can be obtained. The value of the sum of the areas of all valid buffers (ie, service ranges) calculated in ArcGIS software is the value of the corresponding $C_{1}$ indicator.

Effective green space refers to the green space whose total area and effective service area ratio meet the requirements of the Guidelines for Urban Green Space Disaster Prevention and Risk Avoidance Design (Table 3). Count the number of city parks that meet the requirements of the table below to get the value of indicator $C_{2}$.

Table 3. Classification table of design requirements for effective avoidance area of urban disaster prevention and avoidance functional green space

\begin{tabular}{|l|c|c|c|}
\hline Classification & Area (ha) & $\begin{array}{c}\text { Effective } \\
\text { hedging area } \\
\text { ratio }\end{array}$ & $\begin{array}{c}\text { Available safe } \\
\text { haven area per } \\
\text { capita (square } \\
\text { metre/person) }\end{array}$ \\
\hline Long-term & $\geq 50$ & $\geq 60 \%$ & $\geq 5$ \\
\hline Mid-term & $\geq 20$ & $\geq 40 \%$ & $\geq 2$ \\
\hline Short term & $\geq 1$ & $\geq 40 \%$ & $\geq 2$ \\
\hline Emergency & $\geq 0.2$ & $\geq 30 \%$ & $\geq 1$ \\
\hline
\end{tabular}

Note: Reference to guidelines for disaster prevention and risk avoidance design of urban green space issued by The General Office of the Ministry of Housing and Urban-Rural Construction of China.

\section{(2) Rationality of the layout and structure of urban park}

Remote sensing image data and field survey data are still the main sources of data needed in this step. The rationality of urban layout is mainly based on landscape pattern index (O'Neill et al., 1988). The formulas of landscape diversity, evenness, connectivity and aggregation are used to analyze the urban park to evaluate the rationality of its layout structure.

$$
\begin{aligned}
& \text { Diversity of Urban Parks }\left(C_{3}\right): \\
& \text { SHDI }=\sum_{i=1}^{n}\left[P_{i} \ln \left(P_{i}\right)\right],
\end{aligned}
$$

where SHDI represents the diversity of urban parks and $P_{i}$ represents the proportion of each type of parks to the total area of urban parks. 
Uniformity of Urban Parks $\left(C_{4}\right)$ :

$$
E=\frac{-\sum_{i=1}^{m} P_{i} \ln \left(p_{i}\right)}{\ln (m)},
$$

where, $E$ represents the uniformity of urban parks, $P_{i}$ represents the proportion of each type of parks to the total area of urban parks and $m$ represents the total number of park green space types.

Connectivity of Urban Parks $\left(C_{5}\right)$ :

$$
P X=\sum_{i=1}^{n}\left[\frac{A_{i} / N N D i}{\sum_{i=1}^{n} A_{i} / N N D i}\right]^{2},
$$

where, $P X$ represents the connectivity of urban parks, $A_{i}$ represents the area of park $i$ and $N N D i$ represents the minimum distance between park $\mathrm{i}$ and its adjacent park.

Conglomeration Degree of Urban Parks $\left(C_{6}\right)$ :

\section{CONTAG $=$}

$$
\left[1+\frac{\sum_{i=1}^{m} \sum_{k=1}^{m}\left[\left(P_{i}\right) \frac{g_{i k}}{\sum_{k=1}^{m} g_{i k}}\right]\left[\ln \left(P_{i}\right) \frac{g_{i k}}{\sum_{k=1}^{m} g_{i k}}\right]}{2 \ln (m)}\right]
$$

where, CONTAG represents the conglomeration degree of urban parks, $P_{i}$ represents the proportion of each type of parks to the total area of urban parks, $m$ represents the total number of park green space types and $g_{i k}$ represents probability that two randomly adjacent grid parks belong to types $i$ and $k$.

We selected Shannon diversity index (SHDI), evenness $(E)$ index, landscape connectivity index $(P X)$ and landscape aggregation index (CONTAG) in landscape pattern index to analyze the layout structure characteristics of urban park system (O'Neill et al., 1988). The comprehensive use of these landscape pattern indices can well reflect whether a city's park system is rich in species, evenly distributed, interconnected with each other, and whether local parks are relatively clustered. All calculations could be done in the Fragstats software (Estoque et al., 2018). The input data required by the software is the remote sensing image that is classified in the completed land. The calculating results of SHDI, E, PX and CONTAG represent the value of $C_{3}, C_{4}, C_{5}, C_{6}$ respectively.

\section{(3) Connectivity between urban built environment elements and urban parks}

Again, remote sensing image data and field survey data are sources of data needed in the calculation of the connectivity. In the process of calculating the connectivity of urban parks and other built environment elements in cities, we will first examine the ratio of the total number of urban parks to the total length of urban roads. The calculating results of the ratio represent the value of $C_{7}$. The higher the ratio, the higher the overall connectivity.

Then we will use the cost distance in ArcGIS network analysis module to calculate the average shortest distance from the city park to the surrounding disaster relief facilities and other disaster prevention space. The calculation result of the former of the ArcGIS software output is the value of the index $C_{8}$, and the latter is the value of the $C_{9}$ index.

\section{(4) The matching degree between urban built environment elements and the number of urban parks}

The basic data used in this part mainly come from China's various statistical yearbooks and related planning. In the process of discussing whether urban parks and built environment match in quantity, we will count the total number of parks, the density of urban population and the number of urban infrastructure respectively. Their ratio is calculated by dividing operation. The result of dividing the number of urban parks by the urban population density represents the value of the $\mathrm{C}_{10}$ indicator. The result of dividing it by the number of urban infrastructure represents the value of the $C_{11}$ indicator. The bigger the result is, the higher the matching degree is.

\section{(5) Disaster occurrence}

In the process of quantifying the occurrence of disasters, we did not use complex methods to process the data. The data found in the statistical yearbook can well reflect the occurrence of disasters.

The number of natural disasters, man-made disasters, and abnormal environmental events in the past 30 years represent the value of indicator $C_{12}, C_{13}, C_{14}$ respectively.

\section{(6) Disaster severity}

In the process of quantifying the severity of disasters, we have not used complex methods to process the data. The data found in the statistical yearbook (population casualties, economic losses) can well reflect the severity of the impact of disasters.

The number of economic losses caused by previous disasters (in the last 30 years) equals to the value of indicator $C_{15}$. The number of casualties caused by previous disasters represent the value of indicator $C_{16}$.

\section{(7) The completeness of relevant laws and regulations}

It is difficult to quantify whether a city's planning for urban parks, especially for disaster prevention, is sound or not. Therefore, in this study, experts and scholars will be invited to fill in the questionnaire, and the results of the questionnaire will be converted into corresponding scores to quantify the index.

Experts' subjective scores on the integrity of urban green space system planning, disaster prevention planning and other related planning (the scoring criteria are as follows) represent the values of $C_{17}, C_{18}$ and $C_{19}$ indicators, respectively. 
Table 4. Quantification of the completeness of relevant laws and regulations

\begin{tabular}{|l|l|l|l|l|}
\hline \multicolumn{1}{|c|}{ Points } & \multicolumn{1}{|c|}{$1-25$ Points } & \multicolumn{1}{|c|}{$26-50$ Points } & \multicolumn{1}{c|}{ 51-75 Points } & $76-100$ Points \\
\hline Completeness & Deficient & General & Complete & Consummate \\
\hline
\end{tabular}

\section{(8) Urban disaster prevention mechanism}

Urban disaster prevention mechanism is also an abstract index. Like the previous indicator, we intend to invite experts and well-known scholars to conduct a questionnaire survey. And translate their answers into corresponding figures to quantify these indicators.

Experts' subjective scores on the unified command capability and synergistic linkage mechanism of urban park system (the scoring criteria are shown in Table 4) represent the values of $C_{20}$ and $C_{21}$ indicators, respectively.

\subsection{The calculation of disaster prevention capability}

After completing the final quantitative scores of each evaluation index, according to its weight relationship, the weight coefficient and the quantitative score are integrated, and finally the comprehensive score $A$ of disaster prevention and avoidance suitability of the urban park green space system is determined. The specific calculation formula is as follows:

$$
A=\sum_{i=1}^{n} w_{i} s_{i}
$$

where $i$ denotes an evaluation index, $w_{i}$ denotes an evaluation index weight, and $s_{i}$ denotes an evaluation index quantitative score.

Through the suitability evaluation, the general scores of the disaster prevention and avoidance suitability of urban park green space system are compared with other urban park green space systems of the same type, and the overall situation of disaster prevention and avoidance suitability of the urban park green space system is known. At the macro level, grasp the strength of a city park green space disaster prevention capability.

At the same time, the vertical comparison between the evaluation indicators at all levels of the city can clearly understand the inadequacy of the urban park green space system's own disaster prevention and avoidance capabilities. In the future planning and construction, the indicators with lower scores will be upgraded and targeted.

\section{Results}

In order to prove that the evaluation index system designed in this study can accurately measure the disaster prevention and avoidance ability of China's urban park system, and point out the shortcomings of the urban park system, this chapter will use an example study to verify this.

\subsection{Study area}

Based on China's national conditions, this study investigates five cities with high level of parks and green space

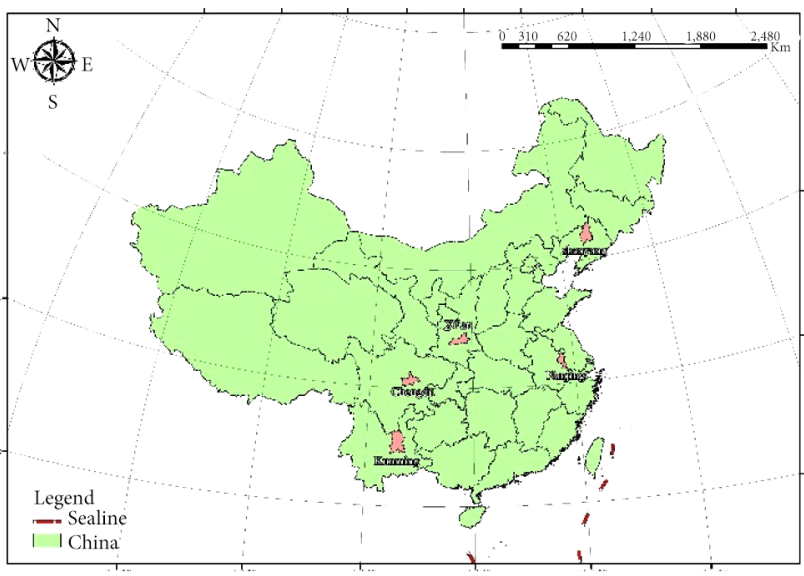

Figure 3. Study area

construction in China, namely Nanjing, Chengdu, Shenyang, Xian and Kunming (Figure 3), and collects relevant data.

In this case study, we selected five provincial capitals in China. They are located in the northeastern, northern, southern, central and eastern parts of China, respectively. By comparing the construction of green space system of urban parks in these regions, we can basically reflect the current situation of green space construction in China. At the same time, we can find the different characteristics of green space construction in different regions of China.

It should be noted that in recent years, Kunming and Chengdu have experienced different degrees of natural disasters. Studying the construction of post-disaster green space in these cities is of great significance to the establishment of urban disaster prevention system.

\subsection{Data normalization}

After defining the object of study, we formally began to use the method proposed in Chapter 2 to calculate and analyze the disaster prevention capability of urban parks in these five Chinese cities. Referring to the quantitative methods mentioned in chapter 2.3.2 and Table 1, we collected the original data of $21 \mathrm{C}$-level indicators in five cities. Then, before calculating the value of the indicators in $A, B$ and $C$ level, it is necessary to normalize the evaluation indicators with different magnitudes and units to get the final quantitative score between [0-1] (Kondo, Fluehr, McKeon, \& Branas, 2018). Normalization is a simplified method of calculation, which transforms the dimensionless expressions into dimensionless pure quantities, so that the indexes of different units or scales can be compared and weighted (Kondo et al., 2018). The Min-Max Normalization Method was introduced to this work. The basic principles of this method are as follows: 


$$
x^{\prime}=\frac{x-x_{\text {min }}}{x_{\text {max }}-x_{\text {min }}},
$$

where $x^{\prime}$ represents the result of normalized calculation; $x_{\text {min }}$ and $x_{\text {max }}$ represent the maximum and minimum values of the measurement results, respectively. The normalized result was shown in Table 5.

Table 5. Normalized result (C Level) of disaster prevention ability of park system in five cities

\begin{tabular}{|c|c|c|c|c|c|}
\hline $\begin{array}{c}\text { Indi- } \\
\text { cators }\end{array}$ & Nanjing & Chengdu & Shenyang & Xi'an & Kunming \\
\hline $\mathrm{C}$ & 0.038 & 0.000 & 0.692 & 0.308 & 1.000 \\
\hline$C_{2}$ & 0.304 & 1.000 & 0.565 & 0.739 & 0.000 \\
\hline$C_{3}$ & 0.309 & 0.528 & 0.059 & 0.000 & 1.000 \\
\hline$C_{4}$ & 0.731 & 0.410 & 0.677 & 1.000 & 0.000 \\
\hline$C_{5}$ & 1.000 & 0.281 & 1.000 & 0.656 & 0.000 \\
\hline$C_{6}$ & 0.080 & 0.070 & 0.020 & 0.000 & 1.000 \\
\hline$C_{7}$ & 0.846 & 0.615 & 1.000 & 0.000 & 0.000 \\
\hline$C_{8}$ & 1.000 & 0.335 & 0.486 & 0.400 & 0.000 \\
\hline$C_{9}$ & 0.941 & 1.000 & 0.176 & 0.059 & 0.000 \\
\hline$C_{10}$ & 1.000 & 0.674 & 0.000 & 0.326 & 0.047 \\
\hline$C_{11}$ & 1.000 & 0.000 & 0.000 & 0.250 & 0.667 \\
\hline$C_{12}$ & 0.000 & 0.565 & 0.904 & 0.856 & 1.000 \\
\hline$C_{13}$ & 0.000 & 0.942 & 0.443 & 0.649 & 1.000 \\
\hline$C_{14}$ & 0.063 & 0.000 & 1.000 & 1.000 & 0.563 \\
\hline$C_{15}$ & 0.954 & 0.031 & 1.000 & 0.262 & 0.000 \\
\hline$C_{16}$ & 0.636 & 0.000 & 1.000 & 0.455 & 0.091 \\
\hline$C_{17}$ & 0.333 & 1.000 & 0.333 & 0.000 & 0.000 \\
\hline$C_{18}$ & 0.281 & 1.000 & 0.375 & 0.000 & 0.469 \\
\hline$C_{19}$ & 0.625 & 0.000 & 0.000 & 0.000 & 1.000 \\
\hline$C_{20}$ & 0.625 & 0.000 & 0.000 & 0.000 & 1.000 \\
\hline$C_{21}$ & 0.000 & 0.000 & 1.000 & 0.667 & 0.333 \\
\hline & & & & & \\
\hline
\end{tabular}

\subsection{Weights calculation}

Next, we calculated the weights of these 21 indicators using the weight determination method designed in chapter 2.2. Each indicator had four weight calculation results. We set the average of the four weight calculation results as the final weight of each index in the study (Table 6).

Table 6. The results of weights calculation in 5 Chinese major cities

\begin{tabular}{|c|c|c|c|c|c|}
\hline $\begin{array}{c}\text { Indi- } \\
\text { cators }\end{array}$ & Expert & AHP & Principal & Entropy & $\begin{array}{c}\text { Final } \\
\text { Weights }\end{array}$ \\
\hline $\mathrm{C}$ & 0.071 & 0.091 & 0.007 & 0.048 & 0.043 \\
\hline$C_{2}$ & 0.073 & 0.091 & 0.007 & 0.127 & 0.065 \\
\hline$C_{3}$ & 0.036 & 0.058 & 0.047 & 0.093 & 0.054 \\
\hline$C_{4}$ & 0.031 & 0.026 & 0.064 & 0.211 & 0.079 \\
\hline$C_{5}$ & 0.047 & 0.071 & 0.084 & 0.101 & 0.070 \\
\hline$C_{6}$ & 0.030 & 0.026 & 0.405 & 0.090 & 0.134 \\
\hline
\end{tabular}

End of Table 6

\begin{tabular}{|c|c|c|c|c|c|}
\hline $\begin{array}{c}\text { Indi- } \\
\text { cators }\end{array}$ & Expert & AHP & Principal & Entropy & $\begin{array}{c}\text { Final } \\
\text { Weights }\end{array}$ \\
\hline$C_{7}$ & 0.068 & 0.089 & 0.001 & 0.269 & 0.098 \\
\hline$C_{8}$ & 0.066 & 0.057 & 0.015 & 0.051 & 0.039 \\
\hline$C_{9}$ & 0.065 & 0.071 & 0.002 & 0.259 & 0.091 \\
\hline$C_{10}$ & 0.070 & 0.073 & 0.026 & 0.118 & 0.063 \\
\hline$C_{11}$ & 0.059 & 0.036 & 0.002 & 0.003 & 0.018 \\
\hline$C_{12}$ & 0.027 & 0.030 & 0.058 & 0.265 & 0.092 \\
\hline$C_{13}$ & 0.024 & 0.030 & 0.084 & 0.009 & 0.034 \\
\hline$C_{14}$ & 0.021 & 0.015 & 0.001 & 0.151 & 0.044 \\
\hline$C_{15}$ & 0.024 & 0.025 & 0.076 & 0.207 & 0.080 \\
\hline$C_{16}$ & 0.028 & 0.050 & 0.029 & 0.015 & 0.027 \\
\hline$C_{17}$ & 0.041 & 0.033 & 0.057 & 0.105 & 0.054 \\
\hline$C_{18}$ & 0.045 & 0.033 & 0.036 & 0.148 & 0.060 \\
\hline$C_{19}$ & 0.044 & 0.016 & 0.000 & 0.234 & 0.068 \\
\hline$C_{20}$ & 0.065 & 0.041 & 0.000 & 0.237 & 0.078 \\
\hline$C_{21}$ & 0.062 & 0.041 & 0.000 & 0.207 & 0.070 \\
\hline
\end{tabular}

\subsection{Disaster prevention capability calculation}

Then, we multiplied the normalized results of each index and the calculation results of comprehensive weights, and calculate the disaster prevention capacity of the five urban park systems in detail according to the classification of the indicators in Table 1. The specific calculation results are shown in Table 7.

Table 7. Disaster prevention capability of urban park system in 5 Chinese cities

\begin{tabular}{|c|c|c|c|c|c|}
\hline $\begin{array}{c}\text { Indi- } \\
\text { cators }\end{array}$ & Nanjing & Chengdu & Shenyang & Xian & Kunming \\
\hline$B_{1}$ & 0.343 & 1 & 1.047 & 1 & 1.258 \\
\hline$B_{2}$ & 2.119 & 1.289 & 1.656 & 2 & 1.756 \\
\hline$B_{3}$ & 2.787 & 1.951 & 0.459 & 0 & 1.663 \\
\hline$B_{4}$ & 2 & 0.674 & 0.576 & 0.713 & 0 \\
\hline$B_{5}$ & 0.063 & 1.507 & 2.505 & 2.563 & 2.347 \\
\hline$B_{6}$ & 1.59 & 0.031 & 0.716 & 0.091 & 2 \\
\hline$B_{7}$ & 1.24 & 2 & 0 & 1.469 & 0.708 \\
\hline$B_{8}$ & 1.073 & 0.257 & 1.667 & 1.333 & 1.701 \\
\hline$A_{1}$ & 2.462 & 2.289 & 2.703 & 3 & 3.013 \\
\hline$A_{2}$ & 4.787 & 2.625 & 1.035 & 0.713 & 1.663 \\
\hline$A_{3}$ & 1.653 & 1.538 & 3.221 & 2.653 & 4.347 \\
\hline$A_{4}$ & 2.312 & 2.257 & 1.667 & 2.802 & 2.41 \\
\hline Overall & 11.214 & 8.709 & 8.626 & 9.168 & 11.433 \\
\hline & & & & & \\
\hline
\end{tabular}

Finally, we got the final score of the suitability of disaster prevention and risk avoidance of urban park systems in these 5 Chinese cities (Figure 4).

In general, the disaster prevention capability of the urban park system of five cities can be divided into two categories: Kunming and Nanjing as the first, Xi'an, Shenyang and Chengdu as the second. The disaster prevention ability of the park system of the first two cities is obviously 


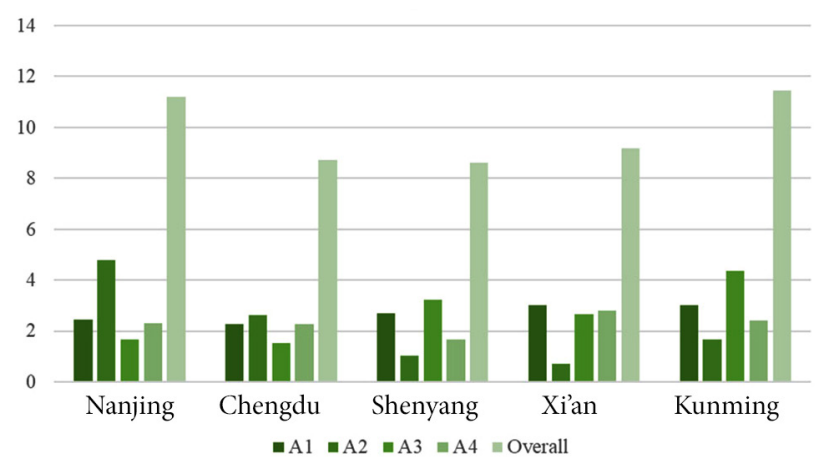

Figure 4. Measuring results of disaster prevention capability of urban park system in five cities

higher than that of the second three cities. The disaster prevention capability of Kunming urban park system is 11.43 , while that of Nanjing is slightly lower than that of Kunming, reaching 11.21. The disaster prevention capability values of the second-tier urban park systems in Xi'an, Chengdu and Shenyang are 9.17, 8.71 and 8.63 , respectively. In the discussion section, we will specifically analyze the specific differences in disaster prevention capabilities of the five urban park systems and the reasons for these differences.

\section{Discussions}

In this chapter, we will discuss in detail the effect of the index system framework designed by us in the practical application, and summarize its advantages and disadvantages in combination with the calculation results of case studies.

\subsection{Discussion on the result of weight calculation}

The results of weight calculation show that there is little difference between the two subjective weight determination methods (Table 5), which also shows that experts and scholars invited in the process of this study basically agree on the recognition of the importance of the indicators in the evaluation index system.

In addition, combined with the data generated by the five cities selected in this case study, the results of the two objective weight determination methods are quite different from each other before, and there are also some differences with the results of the subjective method. This indicates that in this case study, the output values of some indicators may have strong correlation.

The results of four weight determination methods prove that the combination of subjective and objective weight determination methods can more truly reflect the importance of each index in the case study. This is also an important advantage of the index system designed in this study. Dynamic, subjective and objective weights can truly reflect the importance of each component in a system.

Of course, it must be admitted that because the objective weight changes with the original data of each case study, and the calculation process of objective weight itself is more complex, the weight calculation of this index system is indeed more complex and takes more time than other systems.

\subsection{Differences in disaster prevention capability of five cities}

From the calculation results, we can see that the evaluation index system designed by us can accurately compare the disaster prevention ability of different cities, and find the difference of disaster prevention ability of each city.

As the core city in the middle and lower reaches of the Yangtze River, Nanjing has a perfect park system and excellent cooperation between urban parks and other builtup environments. Although it is located along the Yangtze River Valley and suffers from floods all the year round, the overall urban park system is still strong in disaster prevention. Kunming itself is located in Yunnan, China's major disaster-stricken province, but under the support of its urban park system, the disaster-stricken losses of the city are not serious. The index values of urban disaster prevention ability are good. The index of the connection between urban park system and urban elements is not up to the average level, and the overall urban park system is still ranked first in five cities. The number of urban parks in Xi'an, the historical disaster situation and the construction of relevant laws and regulations are excellent, but the relationship between the green space of urban parks and other urban disaster prevention space is very poor, which directly leads to the city's disaster prevention ability only located in the middle reaches of five cities. The situation of Shenyang and Chengdu is comparatively similar, each index level is lower than the average, and the disaster prevention ability of the park system is poor. Because Shenyang is located in the northeast of China, the construction conditions of urban park are general, while Chengdu is still affected by the earthquake because of its close proximity to Wenchuan County, Sichuan Province (Zhang et al., 2015).

\subsection{Numerical analysis of four disaster prevention indexes}

In addition to evaluating the disaster prevention capability and characteristics of urban park green space in different cities, the calculation results of case studies also show that the index system designed by us can accurately find the deficiencies of each urban park green space system in disaster prevention. This is of great significance to urban planning, green space planning and environmental protection.

From the perspective of the quality of urban parks, the level gap between the five cities is very small, and the overall level is relatively high. The green space and ecological construction level of Xi'an and Kunming are relatively high, and the green space quality score is very high, exceeding 3. Nanjing and Chengdu, two new frontier cities 
in China, may focus on urban economic and infrastructure construction in the near future. The quality of green space is low, with only 2.46 and 2.29 respectively. From the point of view of the coupling relationship with the elements of urban construction, there are great differences among cities. The index score of Nanjing reached 4.79, the accessibility of urban green space and other infrastructure was excellent, and the matching degree of quantity, population and other indicators was very satisfactory. The level of coupling between parks and building elements in Kunming and Chengdu is generally 1.67 and 2.62, respectively. There are correlations between urban park and other infrastructures in the two cities.

However, the level of matching between parks green space and other infrastructures in Kunming and Chengdu is general, and there is still much room for improvement. The matching degree of urban park and urban infrastructure in Shenyang and Xian is not ideal, and there is a lot of room for improvement in all aspects. From the historical disaster situation of the city, Chengdu has the lowest score (1.54) because of its close proximity to Wenchuan County. Nanjing along the Yangtze River Basin was severely affected by flooding disasters and scored lower (1.65). The historical disasters in Shenyang and Xi'an are not serious. More unexpectedly, Kunming, as the capital of Yunnan Province, China's disaster-stricken province, got the highest score in this index (4.35). Kunming still has not lost much economy in the case of frequent disasters. The results of questionnaire survey from experts and scholars show that: disaster prevention planning of all other cities is relatively sound except Shenyang.

\section{Conclusions}

Finally, the results showed that:

It is one of the important contents of urban park construction work to improve the disaster prevention and avoidance ability of park green space system efficiently from the urban level. To objectively analyze and evaluate the suitability of urban park green space system for disaster prevention and risk avoidance is the primary task of urban park green space system research, which could provide a preliminary basis and main reference for the planning and construction of park green space system. Therefore, this paper took the urban park system as the research object and constructs a suitability evaluation method for disaster prevention and risk avoidance of urban park green space.

Therefore, based on previous research, this study has constructed a framework for disaster prevention capability assessment of urban park systems applicable to China through rigorous logical reasoning and careful selection of indicators. The framework contains four A-Level indicators and eight B-Level indicators and $21 \mathrm{C}$-Level indicators. We also gave a quantitative method for each indicator and a method for calculating the dynamic weight. Finally, in order to prove the value of every indicator within the evaluation system designed in this study, we have selected five cities in China to conduct an empirical case study. The results showed that the indicator system can not only accurately quantify the disaster prevention capability of the urban park systems, but also discover the shortcomings in the process of urban park system construction, which has strong theoretical and practical value.

Due to the restriction of research conditions and the difficulty of obtaining part of the data, and considering the length of the article, only five Chinese urban parks were studied in the empirical research stage, and no specific analysis and research was conducted on different terrain (mountain, plain) and scale (super large, medium and small-sized) cities. In the future research, we should further consult, collect relevant knowledge, increase the sample richness, and apply more types of urban park green space to the evaluation system of this study. Finally, we will continue to improve the research results and establish a more scientific suitability evaluation system for disaster prevention and avoidance.

\section{Acknowledgements}

The author gratefully acknowledged the financial supports from National Natural Science Foundation of China (Grant Number: NSFC 31200529).

\section{References}

Brink, E., Aalders, T., Ádám, D., Feller, R., Henselek, Y., Hoffmann, A., Ibe, K., Matthey-Doret, A., Meyer, M., Negrut, N. L., \& Rau, A. L. (2016). Cascades of green: a review of ecosystem-based adaptation in urban areas. Global Environmental Change, 36, 111-123.

https://doi.org/10.1016/j.gloenvcha.2015.11.003

Ding, Y., Fan, Y., Du, Z., Zhu, Q., Wang, W., Liu, S., \& Lin, H. (2015). An integrated geospatial information service system for disaster management in China. International Journal of Digital Earth, 8(11), 918-945.

https://doi.org/10.1080/17538947.2014.955540

Elliott, J. R., Walters, R. J., \& Wright, T. J. (2016). The role of space-based observation in understanding and responding to active tectonics and earthquakes. Nature Communications, 7 , 13844. https://doi.org/10.1038/ncomms13844

Estoque, R. C., Murayama, Y., Lasco, R. D., Myint, S. W., Pulhin, F. B., Wang, C., Ooba, M., \& Hijioka, Y. (2018). Changes in the landscape pattern of the La Mesa Watershed - The last ecological frontier of Metro Manila, Philippines. Forest Ecology and Management, 4(30), 280-290.

https://doi.org/10.1016/j.foreco.2018.08.023

Fan, P., Xu, L., Yue, W., \& Chen, J. (2017). Accessibility of public urban green space in an urban periphery: The case of Shanghai. Landscape and Urban Planning, 165, 177-192. https://doi.org/10.1016/j.landurbplan.2016.11.007

Güzey, Ö. (2016). The last round in restructuring the city: Urban regeneration becomes a state policy of disaster prevention in Turkey. Cities, 50, 40-53.

https://doi.org/10.1016/j.cities.2015.08.010

Haaland, C., \& van den Bosch, C. K. (2015). Challenges and strategies for urban green-space planning in cities undergoing densification: A review. Urban Forestry \& Urban Greening, 14(4), 760-771. https://doi.org/10.1016/j.ufug.2015.07.009 
Hoang, L., \& Fenner, R. A. (2016). System interactions of stormwater management using sustainable urban drainage systems and green infrastructure. Urban Water Journal, 13(7), 739758. https://doi.org/10.1080/1573062X.2015.1036083

Kibert, C. J. (2016). Sustainable construction: green building design and delivery. John Wiley \& Sons.

Kondo, M. C., Fluehr, J. M., McKeon, T., \& Branas, C. C. (2018). Urban green space and its impact on human health. International Journal of Environmental Research and Public Health, 15(3), 445. https://doi.org/10.3390/ijerph15030445

La Rosa, D., Privitera, R., Barbarossa, L., \& La Greca, P. (2017). Assessing spatial benefits of urban regeneration programs in a highly vulnerable urban context: A case study in Catania, Italy. Landscape and Urban Planning, 157, 180-192. https://doi.org/10.1016/j.landurbplan.2016.05.031

Li, F., Sutton, P. C., Anderson, S. J., \& Nouri, H. (2017). Planning green space in Adelaide city: Enlightenment from green space system planning of Fuzhou city (2015-2020). Australian Planner, 54(2), 126-133. https://doi.org/10.1080/07293682.2017.1345962

Li, Z. M., Fan, Z. X., \& Shen, S. G. (2018). Urban green space suitability evaluation based on the AHP-CV combined weight method: A case study of Fuping County, China. Sustainability, 10, 2656. https://doi.org/10.3390/su10082656

Liang, Y. (2015). Satisfaction with economic and social rights and quality of life in a post-disaster zone in China: Evidence from earthquake-prone Sichuan. Disaster Medicine and Public Health Preparedness, 9(2), 111-118. https://doi.org/10.1017/dmp.2015.7

O'Neill, R. V., Krummel, J. R., Gardner, R. H., Sugihara, G., Jackson, B., DeAngelis, D. L., Milne, B. T., Turner, M. G., Zygmunt, B., Christensen, S. W., Dale, V. H., \& Graham, R. L. (1988). Indices of landscape pattern. Landscape. Ecology, 1(3), 153-162. https://doi.org/10.1007/BF00162741

Opitz, I., Berges, R., Piorr, A., \& Krikser, T. (2016). Contributing to food security in urban areas: Differences between urban agriculture and peri-urban agriculture in the Global North. Agriculture and Human Values, 33(2), 341-358. https://doi.org/10.1007/s10460-015-9610-2
Ortolano, L. (2017). US urban environmental planning. In The profession of city planning (pp. 144-160). Routledge. https://doi.org/10.4324/9781315134253-17

Rigolon, A. (2016). A complex landscape of inequity in access to urban parks: A literature review. Landscape and Urban Planning, 153, 160-169. https://doi.org/10.1016/j.landurbplan.2016.05.017

Robles, P., Tello, A., Zúñiga-Prieto, M., \& Solano-Quinde, L. (2018, August). Modeling 911 emergency events in CuencaEcuador using geo-spatial data. In International Conference on Technology Trends (pp. 564-577). Cham: Springer. https://doi.org/10.1007/978-3-030-05532-5_43

Smith, C. (2007). Urban disorder and the shape of belief: the great Chicago fire, the Haymarket bomb, and the model town of Pullman. University of Chicago Press. https://doi.org/10.7208/chicago/9780226764252.001.0001

Somma, R., Silvestro, M., Cascio, M., Dawson, L., Donnelly, L., Harrison, M., McKinley, J., \& Ruffell, A. (2016, April). The use of a GIS Red-Amber-Green (RAG) system to define search priorities for burials. In EGU General Assembly Conference Abstracts (Vol. 18, p. 16379). European Geosciences Union.

Thierfelder, H., \& Kabisch, N. (2016). Viewpoint Berlin: Strategic urban development in Berlin-Challenges for future urban green space development. Environmental Science \& Policy, 62, 120-122. https://doi.org/10.1016/j.envsci.2015.09.004

Wei, Y., Huang, C., Li, J., \& Xie, L. (2016). An evaluation model for urban carrying capacity: A case study of China's megacities. Habitat International, 53, 87-96. https://doi.org/10.1016/j.habitatint.2015.10.025

Xiao, Y., Li, Z., \& Webster, C. (2016). Estimating the mediating effect of privately-supplied green space on the relationship between urban public green space and property value: Evidence from Shanghai, China. Land Use Policy, 54, 439-447. https://doi.org/10.1016/j.landusepol.2016.03.001

Zhang, B., Li, N., \& Wang, S. (2015). Effect of urban green space changes on the role of rainwater runoff reduction in Beijing, China. Landscape and Urban Planning, 140, 8-16. https://doi.org/10.1016/j.landurbplan.2015.03.014 